\title{
Using the Environmental Systems Modelling Platform (EnSym) to Assess the Impact of Climate Change on Groundwater in the Port Phillip Region
}

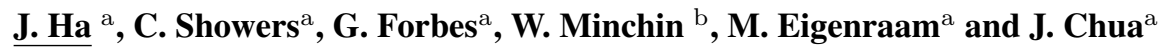 \\ ${ }^{a}$ Department of Sustainability and Environment, 8 Nicholson Street, E. Melbourne, Victoria, Australia \\ ${ }^{\mathrm{b}}$ GHD, 180 Lonsdale Street, Melbourne, Victoria 3000 \\ Email: Joseph.Ha@dse.vic.gov.au
}

\begin{abstract}
This paper describes an application of EnSym (Environmental Systems Modelling Platform) to assess the impacts of climate change on groundwater levels. EnSym is a modular and user-friendly software platform that facilitates the use of environmental modelling tools. It enables easy and rapid evaluation of environmental outcomes due to changes in land management and climatic conditions. It contains a number of toolboxes that deal with different aspects of the environment including land based biophysical processes, groundwater dynamics, spatial and contextual connectivity and finally a set of tools for systematic spatial and temporal reporting. The biophysical modelling (BioSym) toolbox of EnSym is used to estimate the amount of recharge to the groundwater system for specified land use scenarios under specified climatic conditions. The groundwater recharge calculated by BioSym forms the transient inflow to the groundwater system. In this paper, the modular three dimensional finite difference groundwater flow model (MODFLOW) is used to simulate the response of the groundwater system to the transient recharge.

In this paper we report results of simulating climate change scenarios from climate modelling under various emission scenarios and their impact on groundwater levels and storage over time in the Port Phillip CMA of Victoria. The results can be used as a catchment planning tool, a research tool or to aid cost-effective decision-making when planning for future water resource use. The climate data for the Port Phillip region in the coming century have been obtained from the CSIRO downscaled climate modelling carried out for the Climate Futures for Tasmania project. The downscaling processes enables the predictions of future climate with the necessary spatial resolution for understanding changes in rainfall and temperature over Victoria. We consider two emissions scenarios - the A2 (high emissions) and B1 (low emissions) scenarios - from the Intergovernmental Panel on Climate Changes Special Report on Emissions Scenarios. The MODFLOW groundwater model used was sourced from the Victorian Department of Sustainability and Environments ecoMarkets project and operates on a two hundred meter grid cell spacing across $27084 \mathrm{~km}^{2}$ with six model layers.
\end{abstract}

Keywords: Biophysical modelling; BioSym; DFlow; EnSym; groundwater modelling; recharge. 


\section{INTRODUCTION}

For many communities, the development of new water sources increasingly involves the combined use of surface water and groundwater. The effects of excessive and unsustainable groundwater development may not be immediately evident but ultimately can threaten our natural resources. To sustain groundwater as a long-term reliable resource, factors affecting both the quality and quantity of groundwater must be better understood to inform future decision making. These factors include its abundance, distribution, movement and pollution.

It is recognised that groundwater modelling is the best tool to support management of groundwater resources. In the last two decades, there has been a rapid development of the computational tools for groundwater modelling. In most cases these computer programs are very sophisticated, being able to address a wide range of water-related problems very efficiently, provided the appropriate data are available to calibrate models in a reliable manner. The Victorian Government in Australia has just completed a work program to develop reliable groundwater models for all the catchment management regions (watershed) of the State. Groundwater modelling also requires many source and boundary conditions. These include the location of water bodies, evapotranspiration rates and profile, extraction from and recharge to the groundwater system.

The primary aim of this paper is to report on the modelling system that we have developed to integrate surface and subsurface modelling to assess the effects of land use and climatic changes on groundwater. We call this modelling system EnSym - Environmental Systems Modelling Platform. The second aim is to show case how one may use our modelling system to case study the responses of the groundwater system of the Port Phillip region under future climatic conditions. There are many similar studies reported in the literature. For examples, the works of Barron et al. (2010) and Crosbie et al. (2011) reported on the Australian efforts and the work of Herrera-Pantoja and Hiscock (2008) reported on the UK effort to investigate the impact of climate change on groundwater resources.

In this paper, we apply the biophysical modelling (BioSym) toolbox of EnSym to estimate the areal distribution of recharge for use as sources of supply to a groundwater flow and transport model. In this paper, we also take evapotranspiration into account in groundwater modelling. Again, we apply BioSym in supplying the information about the evapotranspiration surface and extinction depth. Different amounts of recharge to the groundwater system and a different evapotranspiration regime will result from different specified land use and climatic scenarios. The groundwater recharge obtained from BioSym forms the transient inflow to the groundwater system. In this paper, the modular three dimensional finite difference groundwater flow model (MODFLOW) is used to simulate the response of the groundwater system to the transient recharge. In this way, the impact of environmental changes on groundwater levels and storage over time can be estimated. The results can be used as a catchment planning tool, a research tool or to aid cost-effective decision making when planning for future water resource use.

\section{ENVIRONMENTAL SYSTEMS MODELLING PLATFORM (EnSym)}

In this section, we will discuss the Environmental Systems Modelling Platform (EnSym) and some of its toolboxes that we have developed for integrated surface and subsurface modelling of the environment at the catchment scale. EnSym is a modular and user-friendly software platform to facilitate the use of environmental modelling tools. It enables easy and rapid evaluation of environmental outcomes due to changes in land management and climatic conditions. It contains a number of toolboxes that deal with different aspects of the environment including land based biophysical process, groundwater dynamics, spatial and contextual connectivity and finally a set of tools for systematic spatial and temporal reporting.

EnSym is developed by the Victorian State Government using a version control system to assist in collaborative development, documentation, and feature tracking. While users do not need to study EnSym's source code, collaborators are welcome to become involved and add new modelling modules, tools and functionalities. The software provides a stand-alone package that allows the user to operate in a "black box" mode, which hides implementation details and usages of the modelling tools. The overlying user interfaces are written in Matlab programming language using a modern design with graphical user interfaces. The environmental modelling tools can be written in any computer programming language. This may, in the long run, contribute to new ways of sharing scientific research. By sharing both data and 
modelling tools in a consistent framework, the integration and application of new modelling tools into environmental and natural resource management will be straight forward.

The input interface of EnSym will automatically subdivide a catchment and then extract model input data from map layers and the associated relational data bases for each catchment. Soils, land use, weather, management, model and topographic data are collected and transferred to appropriate model input variables. These data sets for modelling the Victorian environment had been collected over a number of years by the Victorian Government. The output interface allows the user to display output maps and numerical and graphical output data by selecting a point from the map. Users can thus visualise, interpret and test outputs such as sensitive changes in climate, land use and land management practices through a single interface.

Two of the key toolboxes of EnSym are the biophysical (BioSym) and surface flow (D-Flow) toolboxes. The BioSym toolbox simulates daily soil/water/plant interactions, overland water flow processes, soil loss, carbon sequestration and water contribution to stream flow from both lateral flow and groundwater recharge. The agronomic models can be applied to any combination of soil type, climate, topography and land practice. BioSym can thus be used to evaluate the impacts of climate change, vegetation types (e.g. cropping, grazing, forestry and native vegetation) and land management (e.g. forest thinning and stocking rates) in different parts of the landscape. D-Flow predicts surface water flow directions from digital elevation model (DEM). Flow directions are needed in hydrology to determine the flow paths of water and the movement of sediments, nutrients and contaminants. These two toolboxes of EnSym as well as the groundwater flow model, MODFLOW, are described in the next sections.

\subsection{Biophysical Modelling (BioSym)}

BioSym is a continuous time model that operates on a daily time step. The objective in model development was to predict the impact of management on water, sediment, and agricultural chemical yields in the catchment. To satisfy the objective, the model (a) is physically based (calibration is not possible on catchment scale); (b) uses readily available inputs; (c) is computationally efficient to operate on catchment scale in a reasonable time, and (d) is continuous time and capable of simulating long periods for computing the effects of management changes. The modules in BioSym come from publicly available models. They include CAT (Beverly (2007)), PERFECT (Littleboy et al. (1989)), EPIC (Williams et al. (1989)) and SWAT (Neitsch et al. (2002)). Recently, we upgraded our 3PG+ forest model to its latest version (Feikema et al. (2010)). These models are widely used by the environmental modelling community. The readers are referred to the open literature for references of their developments and model validations.

The physically based models in BioSym provide detailed representations of fundamental processes such as plant growth, infiltration, evapotranspiration, runoff, erosion and sediment transport, nutrient and pollutant transport, stream transport and management practices. By modelling each process separately, the simulation is sensitive to climatic change, land use activities and management changes.

BioSym solves for physical processes conceptually by using simplified analytical solutions and empirical equations. The code for BioSym was written with the objective of simulating all major hydrologic components as simply and realistically as possible, and to use inputs readily available over large spatial scales to enhance the likelihood that the model would become routinely used in planning and water resource decision making.

\subsection{D-Flow}

D-Flow uses the principles of single and multiple flow algorithms, such as Deterministic 8 (D8) and $\mathrm{D} \infty$, to direct the flow from each cell to one or more of its 8 neighbouring cells based on the steepest downslope drop. Efficient algorithms for routing flow over flat areas and through depressions reported in the literature had been implemented and incorporated into the toolbox. D-Flow follows the flow of water in the catchment, from land areas to streams and rivers, through lakes, to estuaries and ultimately to the ocean. The use of D-Flow is to move the runoff from one part of the landscape to the next. Water movement is related to erosion, to sediment, nutrient and pollutant transport. 


\subsection{Groundwater Modelling}

Groundwater modelling uses numerical models that approximate the solutions of governing partial differential equations that describe the flow of water in the aquifer. The aquifer is typically described as a porous medium with varying hydraulic conductivities and water holding capacities. In this paper, the modular three dimensional finite difference groundwater flow model MODFLOW (McDonald and Harbaugh (1988)) is used to simulate the response of the groundwater system to the transient recharge.

\section{SIMULATION RESULTS}

In this section, we present the results of our groundwater modelling of the Port Phillip Catchment Management Authority (PPCMA) region of Victoria, Australia. The PPCMA region covers 12,800 $\mathrm{km}^{2}$ in the south central area of the State of Victoria, encompassing the States capital city, Melbourne. The region is bounded by the Victorian coastline to the south, volcanic plains to the west and high upland areas in the north and east gradually dropping in elevation towards the Port Phillip and and Western Port Bay areas. Geologically the region is simplisitcally divided into two regions, in the south two major depressions, the Port Phillip and Western Port Basins are dominated by deep sedimentary sequences and in the north outcropping pre-Tertiary basement bedrock dominates the upland areas.

The MODFLOW groundwater model used in this assesment was sourced from the Victorian Department of Sustainability and Environments ecoMarkets project (GHD (2010)). The model covers an area of $27,084 \mathrm{~km}^{2}$ with regular model cells $200 \mathrm{~m}$ by $200 \mathrm{~m}$ across 6 model layers. In total 4,062,600 cells were active across the model domain. Boundary conditions consisted of no flow cells along the hydrological northern divide, a general head boundary in the upper most active layer in all offshore areas, stream boundry cells on predefined hydrology, drain cells in areas of man made drainage networks and recharge and evaporation as calculated from EnSym. No lakes or reservoirs were included in the groundwater flow model. Model calibration was achieved through comparison of observed and simulated groundwater levels at 548 bore monitoring sites and baseflow estimates at 18 stream gauging sites. Calibration results indicated a scaled RMS error of $1.7 \%$ overall. A sensitivity analysis was undertaken to assess the effect of varying key parameters on depth to water table and net modelled baseflow. The groundwater model was externally reviewed by Aquaterra Pty. Ltd in line with the MDBA Groundwater Flow Modelling Guidelines.

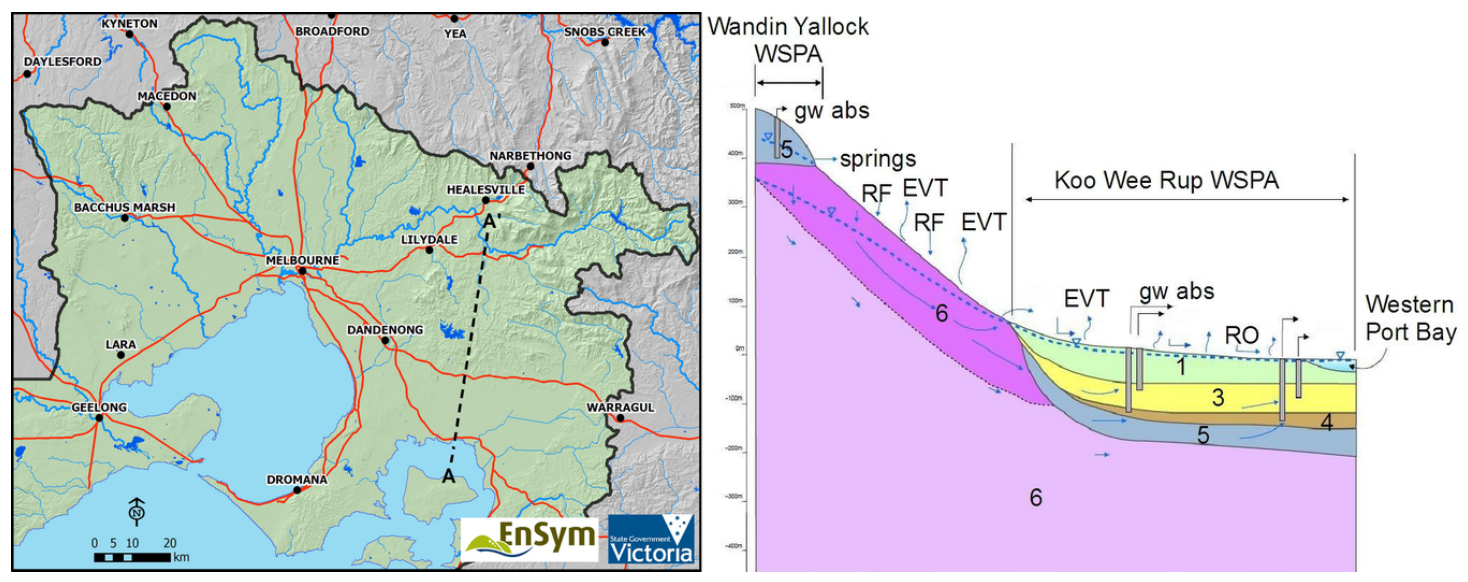

Figure 1. The map shows the groundwater model domain. The dash line A-A' indicates the location of the cross section shown on the right. Cross section A-A (GHD (2010)) on the right shows conceptual model layering from Western Port Bay across the Koo Wee Rup irrigation area up into the Yarra ranges.

The map in Figure 1 shows the whole model domain with the in-active cells displayed in grey. The area to the south west of the map, around Geelong, although outside of the Port Phillip CMA was included in the groundwater model domain as recharge in this area is theorised to discharge into Port Phillip Bay. The figure also shows a conceptual cross section and the relationships between the model layers. 


\subsection{Future Climate}

The climate data for the Port Phillip region in the coming century is obtained from the CSIRO downscaled climate modelling carried out for the Climate Futures for Tasmania project (CFT). The climate simulations provides estimate of the Victorian climate from 1961 to 2100. The CFT project has chosen to use six of the 25 GCMs available from the World Climate Research Programme's Coupled Model Intercomparison Project phase 3 (CMIP3) archive to produce fine-scale climate projections over Tasmania and Victoria. The six GCMs are chosen based on their ability to model current SE Australian climate means and variability. CFT considered the A2 (high emissions) and B1 (low emissions) emission scenarios from the Intergovernmental Panel on Climate Changes Special Report on Emissions Scenarios.

To achieve an average resolution over Victoria and Tasmania of approximately $10 \mathrm{~km}$ for the fine scale simulations, CFT uses the dynamical downscaling technique and conformal cubic grid of the globe. The high resolution climate simulations captures the dynamical relationship between the synoptic patterns and local orographic and other features as well as the evolution of these relationships into the future. The downscaling processes enable the projections of future climate with the necessary spatial resolution for understanding changes in rainfall and temperature over Victoria.

In the modellings presented in this paper, we only use the future climate projections from the CSIROMk3.5 model under the A2 and B1 emission scenarios. In particular, the model period considered here is 2006 - 2020 which is the next 15 year period from the period 1991 - 2005 that was used to developed the groundwater models by the Victorian Government. In Figure 2, the annual means of rainfall, minimum and maximum temperature obtained from the two periods are compared. The climate data from the A2 emission scenario is used for the period $2006-2020$. The results show that future projections indicate general increase in both minimum $\left(0.17-0.3^{\circ} \mathrm{C}\right)$ and maximum $\left(0.2-0.5^{\circ} \mathrm{C}\right)$ daily temperatures. Future projections for rainfall indicates a general increase in the south west and isolated increases in north of the study area but a decrease along a north-west to east band roughly inline with the Great Dividing Range of up to $40 \mathrm{~mm}$.

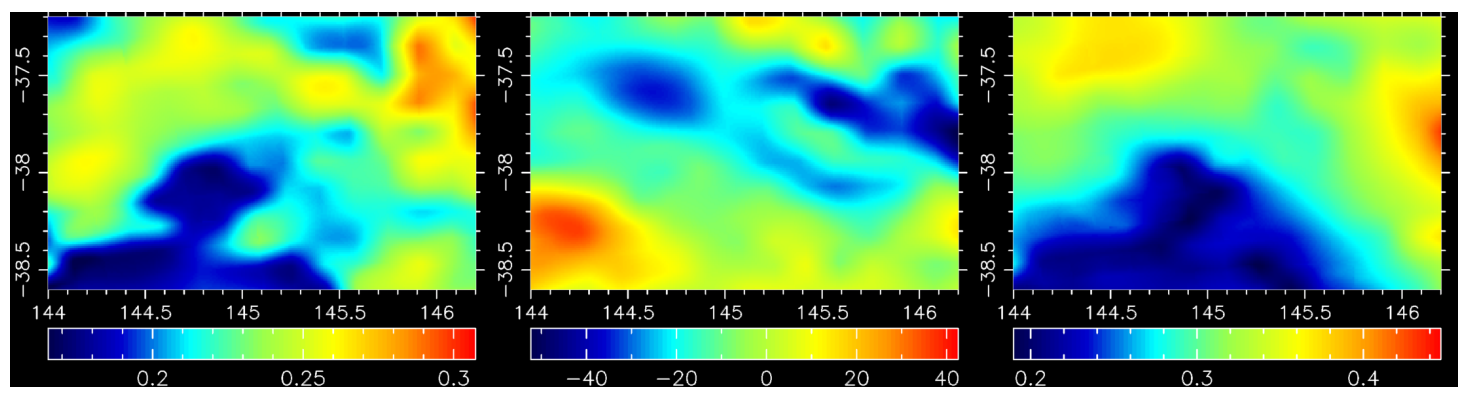

Figure 2. Difference in the annual means between the future (2006 - 2020) and past (1991 - 2005) rainfall (middle figure), minimum (left) and maximum (right) temperature variables. The horizontal and vertical coordinates are in degrees east and north respectively.

\subsection{Modflow Simulations}

Any water from rain and irrigation that are not consumed by vegetation in the landscape, stored in the soil, lost by evaporation or depleted by lateral flow is assumed to be recharge to the groundwater system. This source of water supply to groundwater is estimated from biophysical simulation of the Port Phillip region using BioSym. The BioSym simulation also provides the evapotranspiration surface and extinction depth data for the groundwater modelling using MODFLOW. Typically, BioSym simulation over a 50 year period is carried out. However, groundwater modelling demands much greater computer resources and CPU cycles. In the transient MODFLOW simulations we carried out for this paper, the modelling is done over 180 calendar month stress periods. That is, the Port Phillip groundwater system is simulated for 15 years from the beginning of 2006 to the end of 2020.

In the MODFLOW simulations carried out for this paper, the preconditioned conjugate gradient algorithm is used for solving the simultaneous equations resulting from the finite differencing of the governing 
equations of the groundwater problem. The results of the MODFLOW simulations using past and future climate data are presented in Figure 3. In the figure, the differences in the heads in the uppermost groundwater model layer between future and past predictions from MODFLOW simulations are presented. The comparisons are the difference in the groundwater heads at the end of 2005 and 2020. The two future predictions are from recharge and evapotranspiration data produced by BioSym using future climate data assuming A2 and B1 emission scenarios. Figure 3 shows the head in 2020 is generally lower than that in 2005 near the northern boundary of the Port Phillip region but higher elsewhere.

B1

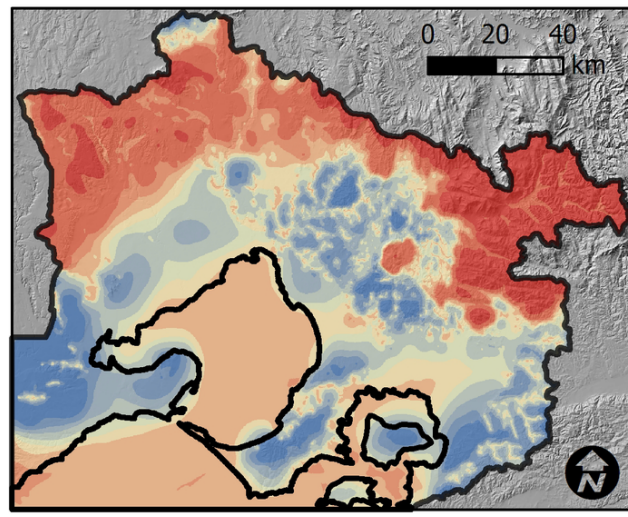

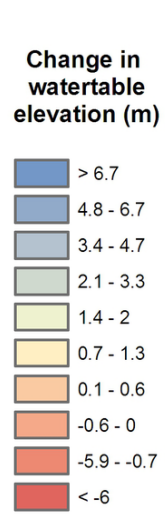

A2

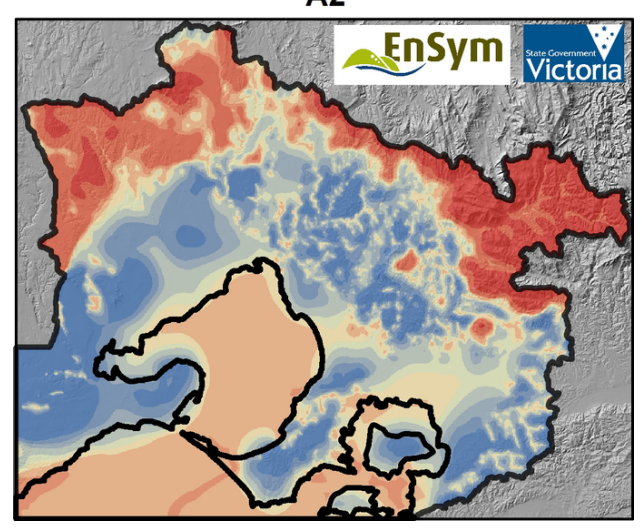

Figure 3. Difference in the head levels at the last stress period of the MODFLOW simulations using the future (2006 - 2020) and past (1991 - 2005) climate data from assuming B1 (left figure) and A2 (right figure) emission scenarios.

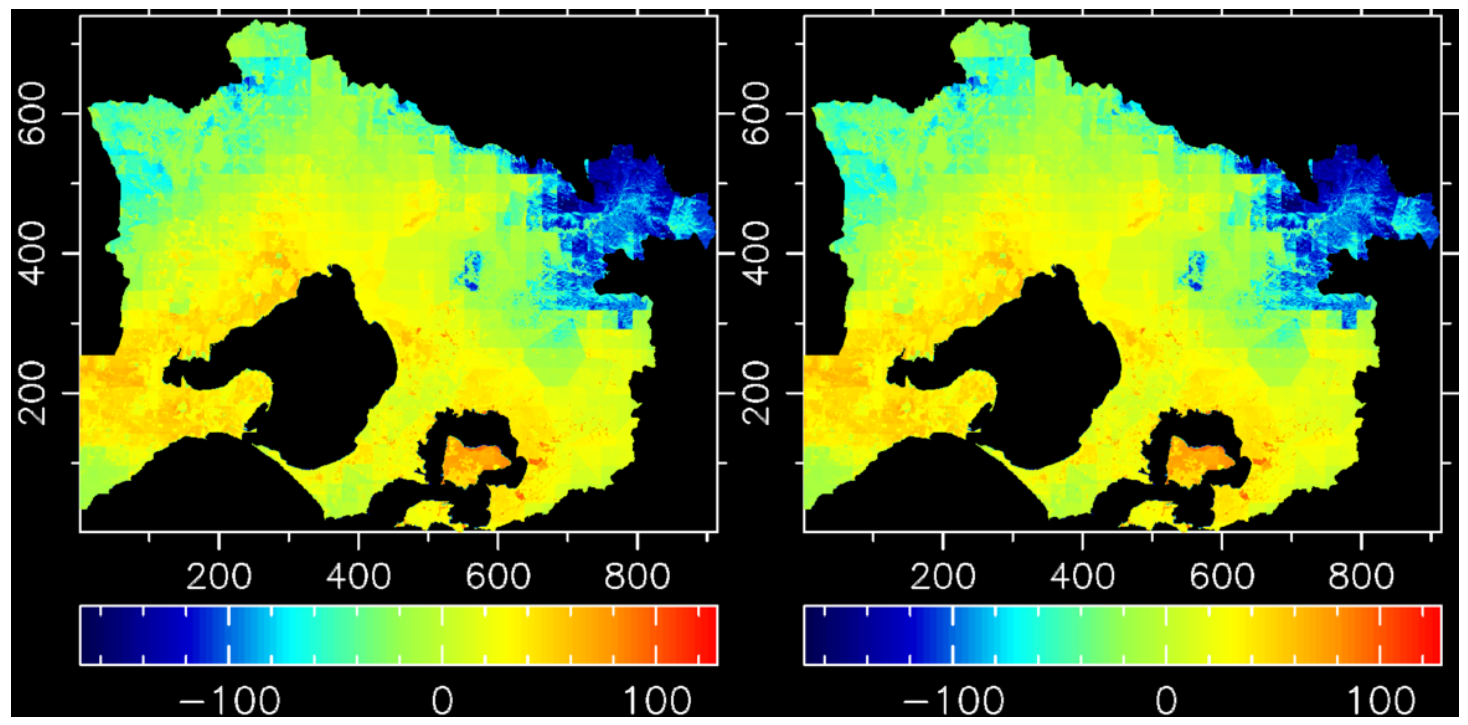

Figure 4. Difference in the annual means between the future (2006 - 2020) and past (1991 - 2005) recharge data using B1 (left figure) and A2 (right figure) climate data.

Inline with the changed distribution of rainfall under both emissions scenarios, recharge has decreased in the ranges to the north east of the study area and increased in the south west. As a result water table elevations, as shown in Figure 3, have increased in general south of the Great Dividing Range but decreased in the higher elevation areas. The 15 year simulation run in this paper is not long enough to see a substantial deviation in results develop between the A1 and B2 emissions scenarios. Global mean nearsurface temperatures within the first half of the 21 st century are roughly consistent across both emissions sceanrios thus major changes in rainfall would not be expected until the later half of the 21 st century. 


\section{CONCLUDING REMARKS}

In Section 2, we present the EnSym (Environmental Systems Modelling Platform) software platform to facilitate the use of environmental modelling tools and some of the toolboxes we have developed for it. Two of the toolboxes we used for obtaining the results for this paper are the BioSym and D-Flow toolboxes. The EnSym software platform can also launch external modelling tool such as MODFLOW that we use for modelling groundwater flow.

In this paper, we show an application example of how EnSym can be used to study the impact of land use and climatic changes on the groundwater system. In particular, we show the integration of surface and subsurface modelling through EnSym to predict environmental outcomes. Using the groundwater model of the Port Phillip region developed by the Victoria Government, the BioSym and D-Flow toolboxes were applied through EnSym to obtain the required recharge and evapotranspiration data for groundwater modelling. The groundwater modelling results obtained in the last section show the projected changes in the head upto 2020 under the A2 and B1 emission scenarios.

Government policy area is one of the key drivers behind the development of EnSym and the continued improvement and validation of its modelling capabilities. This information will be coupled with projected changes in land use and pumping demand to define the effects of several development scenarios on the community's water supply. Once developed, this protocol will enable other communities to decide how to best protect vital groundwater recharge areas, where precipitation replenishes local aquifers. This will also help communities examine how changes in groundwater levels will affect local streams, lakes and wetlands. The environmental systems modelling platform EnSym facilitates the incorporation of the various interactive influences into the resource management decisions. The simulation results presented in the last section demonstrate that EnSym can be used as a catchment planning tool, a research tool or to aid cost-effective decision making when planning for future water resource use.

\section{REFERENCES}

Barron, O., D. Pollock, R. Crosbie, W. Dawes, S. Charles, F. Mpelasoka, S. Aryal, M. Donn, and B. Wurcker (2010). The impact of climate change on groundwater resources: The climate sensitivity of groundwater recharge in Australia. Water for a Healthy Country Report.

Beverly, C. (2007). Technical Manual - Models of the Catchment Analysis Tool. Victorian Department of Sustainability and Environment.

Crosbie, R., J. McCallum, and G. Walker (2011). The impact of climate change on dryland diffuse groundwater recharge in the Murray-Darling Basin. Waterlines Report Series No 40.

Feikema, P., J. Morris, C. Beverley, T. Baker, and P. Lane (2010). Description of the 3PG+ forest growth model. Department of Forest and Ecosystem Science, The University of Melbourne.

GHD (2010). ecoMarkets Port Phillip Groundwater Model, Transient MOdel Development Report. Economics Policy Branch, Victorian Department of Sustainability and Environment.

Herrera-Pantoja, M. and K. Hiscock (2008). The effects of climate change on potential groundwater recharge in great britain. Hydrological Processes 22, 73-86.

Littleboy, M., D. Silburn, D. Freebairn, D. Woodruff, and G. Hammer (1989). PERFECT - A Computer Model of Productivity Erosion Runoff Functions to Evaluate Conservation Techniques. Queensland Department of Primary Industries.

McDonald, M. and A. Harbaugh (1988). A modular three-dimensional finite-difference groundwater flow model. US Geological Survey Techniques of Water-Resources Investigations.

Neitsch, S., J. Arnold, J. Kiniry, J. Williams, and K. King (2002). Soil and Water Assessment Tool Theoretical Documentation Version 2000. Texas Water Resources Institute.

Williams, J., C. Jones, J. Kiniry, and D. Spanel (1989). The epic crop growth model. Transactions American Society of Agricultural Engineers 32, 497-511. 